\title{
Relato de Experiência da Aplicação da Metodologia Ativa de Ensino com Pesquisa na Disciplina de Sistemas de Informação
}

\author{
Felipe M. Sampaio ${ }^{1}$, Jefferson P. de Almeida ${ }^{1}$ \\ ${ }^{1}$ Instituto Federal do Rio Grande do Sul (IFRS) - Campus Farroupilha \\ Farroupilha - RS - Brasil \\ \{felipe.sampaio, jefferson.almeida\}@farroupilha.ifrs.edu.br
}

\begin{abstract}
Resumo. Este artigo apresenta um relato da experiência da aplicação da metodologia ativa de Ensino com Pesquisa como instrumento da prática docente, com o objetivo de aprimorar o processo de ensino-aprendizagem. Os princípios básicos desta metodologia foram utilizados como base para o planejamento da prática docente em uma turma de ensino técnico da área de informática, na disciplina de Sistemas de Informação. Como base para as atividades de sala de aula, dois projetos de pesquisa foram elaborados como elementos norteadores do processo de ensino-aprendizagem segundo a metodologia utilizada. Como reflexões sobre a experiência da aplicação da estratégia de Ensino com Pesquisa, notou-se um aumento na participação os dos alunos, tanto na realização quanto na proposição de atividades. O professor teve seu papel perante os estudantes modificado, atuando agora como um orientador das atividades de pesquisa desenvolvidas em sala de aula. No que tange o processo de acompanhamento das atividades e de avaliação da aprendizagem, ocorreu uma valorização maior ao percurso investigativo percorrido pelo aluno, dado pela organização metodológica das atividades de acordo com as etapas do método científico.
\end{abstract}

\begin{abstract}
This paper presents an experience report of the active methodology "Teaching with Research" with the goal of improving the teching-learning process. The basic principles of this methodology were utilized as basis for the teaching planning for the Information Systems course in an informatics technician class. Two research projects were elaborated as guiding elements of the teaching-learning process (according to the adopted methodology). As reflections regarding the methodology application experience, it could be noticed increased participation of the students during the class activities. The professor has a modified role towards the students: acting like an advisor, guiding the developed research activities inside the classroom. With respect to the learning evaluation methods, it happened an increased valorization of the research path coursed by the student, mainly due to the methodologic organization of the proposed activities (based on the steps of scientific method).
\end{abstract}

\section{Introdução}

Metodologias tradicionais de ensino, fortemente baseadas na transmissão de conhecimentos, privam os alunos de processos mentais que são imprescindíveis na construção das suas representações próprias do conhecimento. Da mesma maneira que crianças necessitam agir sobre o mundo de forma a experimentá-lo das mais diferentes formas, a sala de aula também deve proporcionar oportunidades para que os alunos 
realizem suas investigações e experiências (BECKER; MARQUES, 2007). Além disso, a partir de metodologias de ensino que incorporem estes processos de construção do conhecimento, abre-se a oportunidade para que os resultados dos procedimentos de avaliação da aprendizagem se detenham mais no acompanhamento do percurso do aluno, não sendo apenas o produto da reprodução mecânica dos conceitos apreendidos (LUCKESI, 2011).

Neste sentido, pesquisadores da área da educação vêm desenvolvendo metodologias de ensino diferenciadas (chamadas de metodologias ativas), as quais consideram o aluno como um agente pesquisador e um solucionador de problemas dentro do processo de ensino-aprendizagem. Este trabalho foca, em especial, em metodologias que incorporam aspectos inerentes da pesquisa científica, utilizando-a como instrumento para as atividades de sala de aula. Esta teoria é chamada de Ensino com Pesquisa e tem como pilar fundamental o uso dos procedimentos típicos do método científico para promover a (re)construção do conhecimento (DEMO, 1991).

A área de computação tem um potencial especial quando consideramos o uso de metodologias ativas. Considerando especificamente a metodologia de Ensino com Pesquisa, há imensas oportunidades em disciplinas da computação para o uso desta estratégia, principalmente quando se considera o incentivo à problematização e o uso de raciocínio lógico estruturado. Como estudos de caso, vários trabalhos da literatura trazem relatos e análises de experiências na aplicação de metodologias ativas em disciplinas da computação, demonstrando o interesse acadêmico na aplicação de tais estratégias nesta área do conhecimento (LIMA et al, 2016; BRANDÃO; NEVES, 2014; SANTOS; COSTA, 2006).

Neste contexto, este trabalho tem como objetivo relatar experiências e realizar uma reflexão sobre as contribuições da aplicação na prática docente da metodologia baseada no Ensino com Pesquisa, como forma de aprimoramento do processo de ensino-aprendizagem. Esta reflexão se dará por meio de um relato de experiência da prática pedagógica em uma turma de ingressantes do Curso Técnico em Informática Integrado. A metodologia foi aplicada na disciplina de Sistemas de Informação, a qual pertence ao núcleo técnico do curso.

\section{Referencial Teórico}

A estratégia pedagógica de Ensino com Pesquisa se vale dos princípios educativos da pesquisa científica para o aprimoramento da prática docente (DEMO, 1991). Nesta metodologia de ensino, professores e alunos realizam constantemente as etapas definidas pelo método científico nas atividades de sala de aula. O objetivo é promover a construção, desconstrução e reconstrução do conhecimento a partir de planejamentos de pesquisa realizados previamente. Estes planejamentos são construídos a partir de temáticas que sejam resultantes do programa da disciplina e são constituídos de modo a mobilizar e despertar o interesse dos alunos por meio do processo investigativo. Tem-se, desta forma, um processo de ensino-aprendizagem conduzido na direção de um conhecimento metódico, formado a partir de situações no universo da pesquisa científica (POZO; CRESPO, 2009).

Considerando o caráter educativo da pesquisa, vale ressaltar que a construção do processo de investigação e o desenvolvimento das etapas metodológicas são tão, ou até 
mais, importantes do que propriamente os resultados alcançados. Desta forma, critérios adotados para avaliação da aprendizagem, quando inseridos neste contexto, devem levar em conta um acompanhamento processual das atividades, levando em conta o entendimento e a desenvoltura dos estudantes perante às etapas de construção do conhecimento (LIMA, 2000).

Um dos grandes benefícios desta estratégia, quando trazida para o aperfeiçoamento da prática docente, é a transformação do papel do aluno dentro da sala de aula. Agora, ele se torna um agente participante do processo construtivo do conhecimento (DEMO, 1991). Desta forma, há um incentivo ao desenvolvimento de sua atitude de pesquisa, fazendo com que o estudante aprimore cada vez mais sua "capacidade de aprender a aprender" (LIMA, 2000).

O docente, quando imerso nesta metodologia de ensino, deve organizar os encontros de sala de aula como se estivesse em processo de orientação dentro de um grande grupo de pesquisa. O professor orientador tem como papel, para cada uma das atividades investigativas planejadas, agir de modo a acompanhar seus alunos nas seguintes tarefas: (1) coleta e catalogação de material para embasar as atividades, (2) incentivo aos estudantes para eles mesmos elaborarem suas próprias interpretações acerca dos estudos realizados, (3) insistência para a (re)construção do conhecimento e, por fim, (4) desafio à turma de estudantes para que eles próprios possam elaborar suas próprias impressões e conclusões sobre a atividade (DEMO, 2011).

É condição fundamental para a organização das atividades na metodologia de Ensino com Pesquisa a construção de projetos de pesquisa norteadores (LIMA, 2000). O programa da disciplina deve ser encarado de forma a se descobrir possibilidades para problematização e para a sistematização das atividades de acordo com a metodologia científica. A elaboração destes projetos deve ser realizada, sempre que possível, em cooperação com os estudantes. Inclusive, é desejável que, dependendo da carga horária de trabalho com a turma, os próprios estudantes problematizem questões referentes ao conteúdo a ser trabalhado e, eles mesmos, construam o planejamento metodológico da atividade.

De acordo com Lima (2000), alguns itens imprescindíveis para uma correta elaboração de um projeto de pesquisa, quando utilizado para princípios educativos, estão relacionados à forma de execução da atividade investigativa. Inicialmente, um planejamento de pesquisa deve ser delimitado, trazendo para os alunos qual o tema a ser abordado, o problema (ou a pergunta) de pesquisa que será trabalhada, as justificativas e motivações para o projeto e os objetivos a serem alcançados. Ademais, detalhes referentes à metodologia que será adotada para a execução da atividade investigativa devem ser trazidos, tais como: formulação de instrumentos de coleta, formas para o tratamento dos materiais e dos dados adquiridos, bem como a construção de descrições e análises capazes de fundamentar as conclusões alcançadas.

\section{Metodologia}

Esta seção tem como objetivo descrever a metodologia utilizada neste trabalho. Este artigo engloba o relato das experiências da prática docente na turma de primeiro ano do Curso Técnico em Informática Integrado, mais especificamente na disciplina de Sistemas de Informação. A turma era composta por 34 estudantes. O período da prática 
docente nesta turma totalizou uma carga horária de 30 horas. Vale ressaltar que a disciplina tem o período anual com carga horária de 64 horas.

A disciplina de Sistemas de Informação é parte integrante do núcleo técnico do currículo do Curso Técnico em Informática Integrado. Dentre aqueles especificados para a disciplina no Plano de Ensino, o período da prática docente relatado neste trabalho aborda os seguintes objetivos específicos: (1) Aplicação da tecnologia da informação como base para a construção de sistemas de informação e (2) Estabelecimento de relações entre a evolução histórica da área de computação (e dos sistemas de informação) com os impactos na sociedade contemporânea.

Conforme definido na fundamentação teórica, a prática pedagógica utilizando a metodologia de Ensino com Pesquisa está baseada na formulação de projetos de pesquisa como elementos norteadores das atividades de sala de aula. Para cada um dos objetivos adotados para a prática docente (apresentados na Seção 3) foi elaborado um projeto de pesquisa.

Os projetos foram construídos e organizados em três partes principais. Inicialmente, (1) um planejamento da metodologia de pesquisa que seria utilizada foi definido, especificando o tema de pesquisa, a pergunta (ou problema) de pesquisa, os objetivos e a metodologia que seria adotada. Após, (2) um cronograma das aulas foi definido, apresentando em uma forma sistematizada a divisão das atividades propostas ao longo do tempo. Por fim, (3) detalhes sobre os procedimentos de avaliação da aprendizagem foram especificados, indicando os instrumentos e os critérios de avaliação que seriam utilizados ao longo do desenvolvimento do projeto de pesquisa em questão.

Sempre no início da execução de cada um dos dois projetos elaborados, um tempo da primeira aula era destinado à discussão coletiva dos mesmos. Nestes momentos, todos os detalhes eram passados aos alunos, que tinham a oportunidade de contribuir com sugestões ou alterações nas especificações. Uma vez finalizada a construção do projeto, este era disponibilizado a todos por meio do ambiente virtual de aprendizagem utilizado pela instituição. A cada aula, os principais tópicos do projeto eram relembrados, sempre com a ideia de tornar aquela aula específica parte integrante e fundamental para o alcance dos objetivos definidos no projeto.

A seguir, os dois projetos de pesquisa elaborados e trabalhados em sala de aula, como parte necessária para a aplicação da metodologia de Ensino com Pesquisa, serão apresentados.

\subsection{Primeiro Projeto de Pesquisa: "Impactos da Evolução dos Computadores e dos Sistemas de Informação"}

O resumo da etapa de planejamento do primeiro projeto de pesquisa está apresentado no Quadro 1. Este projeto foi construído para tratar de diversos conteúdos programáticos definidos no Plano de Ensino da disciplina, como o histórico da evolução dos computadores e dos sistemas de informação, bem como os impactos desta evolução na sociedade contemporânea. 
Quadro 1 - Resumo da Etapa de Planejamento do Projeto de Pesquisa

"Impactos da Evolução dos Computadores e dos Sistemas de Informação"

Tema: Impactos da Evolução dos Computadores e dos Sistemas de Informação

Pergunta de Pesquisa: Como as evoluções tecnológicas, principalmente aquelas relacionadas com a evolução dos computadores e dos sistemas de informação, tem impacto nas relações sociais e de trabalho dos dias de hoje?

Objetivos:

- Compreender as principais evoluções tecnológicas da computação e dos sistemas de informação nas últimas décadas;

- Refletir sobre os recentes avanços tecnológicos na área da computação, relacionando com suas consequências no dia a dia da sociedade;

- Se posicionar perante os pontos positivos e negativos de tais evoluções.

Metodologia: As reflexões acerca da temática serão baseadas em três recursos: (1) filme que aborda o tema; (2) texto que propõe discussões sobre o assunto; e (3) momentos em sala de aula para a compreensão do percurso tecnológico recente dos computadores. Para cada um destes três recursos serão realizadas atividades para registro dos pontos principais.

Como metodologia de trabalho, as atividades de orientação por parte do docente considerou a oferta de diferentes subsídios para a reflexão pessoal do aluno. Como um dos instrumentos, foi trabalhado o episódio "Fifteen Million Merits", do seriado britânico Black Mirror, o qual apresenta uma realidade alternativa onde os personagens vivem mais intensamente a vida virtual do que propriamente a vida real. Além disso, críticas ao consumismo e à manipulação midiática perante à sociedade são apresentadas. Outros instrumentos pedagógicos também foram utilizados, como: a leitura e a discussão de um artigo sobre o uso desenfreado das Tecnologias de Comunicação e Informação (ANDRADE; SILVA, 2008), bem como a construção coletiva de cartazes a partir das reflexões individuais sobre os materiais estudados.

Todas as atividades desenvolvidas observam os fundamentos de orientação, definidos pela metodologia de Ensino com Pesquisa: a atuação do docente como orientador das atividades, criando um clima de investigação e pesquisa dentro da sala de aula. Apenas as aulas iniciais tiveram o perfil expositivo, com o objetivo de apresentar os conceitos básicos sobre as dinâmicas que seriam trabalhadas.

\subsection{Segundo Projeto de Pesquisa: "Identificação de Demandas e Proposição de Sistemas de Informação"}

O Quadro 2 apresenta o resumo da etapa de planejamento do segundo projeto de pesquisa aplicado como instrumento da prática docente no campo prático deste trabalho. Neste projeto, as habilidades de problematização e identificação de demandas por sistemas informatizados foram desenvolvidas. Além disso, após o reconhecimento das necessidades, os alunos deveriam propor sistemas de informação que pudessem ser empregados nestes campos. 


\section{Quadro 2 - Resumo da Etapa de Planejamento do Projeto de Pesquisa}

"Identificação de Demandas e Proposição de Sistemas de Informação"

Tema: Identificação de Demandas e Proposição de Sistemas de Informação

Pergunta de pesquisa: Cada grupo, de acordo com a demanda identificada, deveria elaborar o seu próprio problema (pergunta) de pesquisa a ser investigado durante o desenvolvimento do projeto.

Objetivos:

- Identificar problemas/necessidades que podem ser solucionados através de um sistema de informação;

- Propor uma problematização do cotidiano na busca por deficiências que possam ser aprimoradas por sistemas computacionais;

- Incentivar a criatividade na proposição de soluções de sistemas de software.

Metodologia:

- Formação de grupos de trabalho: 3 integrantes;

- Acompanhamento aula a aula: em cada aula serão apresentados detalhes de como construir cada etapa do planejamento da pesquisa;

- Etapas que deverão ser vencidas para a conclusão do projeto: Definição do tema, Problema, Justificativas, Objetivos, Metodologia, Referências

- Produtos do projeto: Apresentação para a turma: entre 5 e 10 minutos. Construção de um relatório (no Moodle/Google Docs) do resultado de cada uma das etapas do projeto.

Este trabalho, além de empregar os conceitos da metodologia de Ensino com Pesquisa na construção das atividades, também proporciona aos alunos a construção de seus próprios planejamentos científicos. A partir de demandas identificadas pela própria turma, os alunos se organizaram em grupos nos quais o objetivo foi o de planejar a construção de um software que contribuísse para a resolução da problemática definida inicialmente. De forma a prover um contato ainda maior com o método científico, o planejamento do desenvolvimento do software deveria ser feito em forma de um planejamento de pesquisa. Como produtos finais, foi pedido um relatório com cada uma das etapas do planejamento, bem como a construção de uma apresentação dos resultados de cada grupo para o restante da turma.

As atividades de sala de aula tiveram como objetivo instrumentar os alunos com detalhes mais práticos das etapas de planejamento da pesquisa: definição do tema, problematização, construção de justificativas e motivações, especificação de objetivos e planejamento metodológico. A dinâmica adotada para as aulas foi a seguinte. Os momentos iniciais dos encontros eram destinados a uma discussão sobre cada uma das etapas da metodologia científica. Após, de acordo com a temática escolhida por cada grupo, os alunos trabalhavam na construção desta etapa metodológica em seus próprios projetos. A prática docente para estes momentos era dada pela orientação grupo a grupo, auxiliando-os a organizar suas ideias e pesquisa em forma de planejamento científico.

Para prover um acompanhamento processual na construção de cada uma das etapas, um cronograma de entregas parciais foi elaborado. Após cada entrega parcial, o professor retornava aos alunos uma série de sugestões para a melhoria da etapa em questão. Este retorno tinha como objetivo contribuir com a construção dos alunos, orientando-os na correta elaboração das suas ideias. Desta forma, os produtos finais deste projeto foram finalizados já com uma série de contribuições do professor, 
aumentando a qualidade final dos trabalhos. A última aula foi destinada a uma rodada de discussões com cada grupo. Nestas rodadas, o professor passou os pontos positivos e negativos que observou ao longo do processo.

\section{Relato das Experiências e Discussões}

O objetivo desta seção é, sob a luz dos conceitos teóricos trazidos na fundamentação deste artigo (Seção 2), relatar as experiências vividas na aplicação da metodologia de Ensino com Pesquisa como forma de aprimoramento da prática docente. Como forma de sistematização das observações realizadas, foram elaboradas notas de campo baseadas na metodologia de Bogdan e Biklen (1998).

\subsection{Indissociabilidade entre Ensino e Pesquisa}

Embebidos das noções básicas de como as atividades se dariam, criou-se um clima de trabalho e de constante descoberta na sala de aula. Ao longo do primeiro projeto, por exemplo, quando vários materiais foram trabalhados sob a mesma problemática (impactos da computação na sociedade), cada estudante teve a oportunidade de se munir de evidências para que, no fechamento do projeto, ele pudesse elaborar suas próprias conclusões sobre o tema. Da mesma forma, ao longo do segundo projeto, os alunos trabalharam em forma cooperativa, criando um ambiente de construção de ideias, com o objetivo de elaborar sistemas informatizados para serem empregados nas demandas levantadas pelos próprios alunos.

Vale ressaltar também o especial potencial de melhoria no ensino em disciplinas da área de informática quando utilizada a metodologia de Ensino com Pesquisa. Para os conteúdos que foram trabalhados no campo prático deste trabalho, a adaptação e elaboração dos projetos de pesquisa se mostraram diretas. Tipicamente, alunos enfrentam problemas com o raciocínio lógico e com os conceitos iniciais da área de computação. Desta forma, quando a sua atuação como estudante é guiada por um trabalho metódico o seu percurso escolar se torna mais natural.

\subsection{Trabalho de Sala de Aula Conduzido por Projetos de Pesquisa}

A elaboração dos projetos de pesquisa para o trabalho com a metodologia de Ensino com Pesquisa em sala de aula se mostrou bastante satisfatória. Do ponto de vista da construção (conduzida pelo docente), criou-se um momento de reflexão sobre o percurso didático que deveria ser oferecido aos alunos ao longo do trabalho de sala de aula. Este caminho foi especificado em forma de planejamentos científicos, contendo a descrição de todas as etapas metodológicas da pesquisa. Comparando com a simples aplicação do que foi pensado para o Plano de Ensino, foi possível notar uma melhor organização dos trabalhos de sala de aula.

Outra contribuição importante está relacionada com o entendimento dos alunos sobre o que seria trabalhado ao longo das aulas. Apresentar, discutir e aprimorar estes projetos em conjunto com a turma foi de essencial importância para uma maior integração e participação dos estudantes nas atividades desenvolvidas. Como mencionado anteriormente, decidiu-se incorporar dentro dos projetos de pesquisa informações sobre o cronograma das aulas e os critérios de avaliação que seriam adotados. Esta interconexão de informações compiladas em um único documento, bem como a sua disponibilização para a turma no início da execução do projeto, foi de 
extrema importância para bom andamento da aplicação da metodologia de Ensino com Pesquisa.

\subsection{Atuação do Professor como Orientador}

Os encontros de sala de aula foram planejados para terem um clima de trabalho como se todos estivessem em um grande grupo de pesquisa. Em alguns momentos, como planejado, metodologias expositivas foram utilizadas para definir e delimitar os aspectos fundamentais das atividades. De forma geral estes momentos foram diluídos ao longo das aulas, geralmente acontecendo nos momentos iniciais de cada encontro.

Ao longo das atividades, o principal papel do docente foi o de orientação do percurso dos estudantes pelos conteúdos, conceitos e raciocínios que deveriam ser percorridos. Pensando no espaço físico tradicional da sala de aula, a área de atuação do professor saiu da parte frontal da sala e se deu de forma mais intensa em meio aos alunos, participando e orientando as discussões internas nos grupos de trabalho. Isso proporcionou um contato mais próximo com a turma, quando as conversas tinham um clima menos formal, abrindo espaço para uma grande troca de ideias.

\subsection{Aluno como Partícipe do Processo}

O ambiente de investigação e de criação impulsionado pela metodologia de Ensino com Pesquisa mobilizou de forma satisfatória o envolvimento dos alunos. Foi com os apontamentos deles que se chegou ao episódio do seriado britânico que foi trabalhado no primeiro projeto. Foram através de sugestões da turma que se implementou o sistema de construção dos relatórios por etapas, com avaliações parciais de cada etapa do trabalho. Foi por meio de ideias dos estudantes que se definiram as problemáticas que foram abordadas no segundo projeto trabalhado. Desta maneira, observou-se que a metodologia aplicada tirou do professor o papel centralizador de propor e de definir, por si só, como se daria o andamento do processo de ensino-aprendizagem.

\subsection{Percurso de Construção do Conhecimento e Processo Avaliativo}

Um principais pontos positivos encontrados durante a aplicação da metodologia de Ensino com Pesquisa foi a possibilidade de avaliação do percurso percorrido pelos alunos. Mais importante do que o resultado final, o qual poderia ser avaliado por um exame final, foi o desempenho e a evolução dos alunos ao longo do processo.

Exemplificando, o primeiro projeto previa como metodologia de trabalho uma avaliação final individual. Ao longo do processo, diversas atividades foram desenvolvidas com o objetivo de instrumentar os alunos com materiais e com reflexões a partir de diferentes pontos de vista. Cada uma destas atividades "parciais" gerou um pequeno registro, onde o professor pôde acompanhar os "resultados parciais" obtidos pelo aluno. A avaliação final foi construída de forma a reunir os resultados cada uma destas atividades: os alunos, inclusive, puderam consultar seus registros. Desta forma, mais do que uma avaliação de aprendizagem ao final, diferentes procedimentos foram aplicados para o acompanhamento do andamento do processo investigativo realizado.

No segundo projeto de pesquisa desenvolvido nas aulas, uma estrutura de entregas parciais, juntamente com o respectivo retorno do docente, foi implementada também no sentido de se ter um acompanhamento dos alunos. Neste caso, o professor 
retornava aos alunos um parecer descritivo com a sua avaliação daquela etapa específica, juntamente com correções e com sugestões de melhoria. A avaliação final do aluno foi composta grande parte por estes acompanhamentos parciais, tendo um grande peso na nota final de cada estudante.

De forma geral, foi natural a construção de uma metodologia avaliativa que levasse em conta o processo de ensino-aprendizagem como um percurso do aluno. Por trazer os aspectos educativos da pesquisa científica para a sala de aula, sendo estes fortemente baseados em etapas metodológicas definidas, foi possível observar de forma mais clara a evolução do discente ao longo do processo.

\subsection{Dificuldades Encontradas}

Apesar dos inúmeros benefícios discutidos anteriormente sobre a aplicação da metodologia de Ensino com Pesquisa, algumas outras questões importantes devem ser levadas em consideração. O desenvolvimento desta estratégia em uma turma com muitos alunos torna o acompanhamento por parte do docente mais complexo. Por exigir tarefas de orientação intensas por parte do professor, cada minuto de sala de aula deve ser aproveitado ao máximo. Desta forma, seguir o planejamento adotado é essencial para que se dê uma boa orientação aos alunos.

Outro ponto importante está relacionado à maturidade dos alunos para o entendimento das etapas metodológicas da pesquisa científica. Este aspecto foi constatado no campo prático deste trabalho, visto que o alunos, em sua grande maioria, eram egressos do ensino fundamental com faixa etária entre 14 e 16 anos. Tornou-se desafiador a tarefa de desmistificar a pesquisa científica perante este perfil de turma. Contudo, observou-se alguns resultados extremamente satisfatórios, pois alunos souberam se expressar organizando seus relatos de acordo etapas metodológicas da pesquisa. Entretanto, alguns outros alunos tiveram bastante dificuldade em estabelecer com clareza tais etapas, o que foi observado de forma mais latente no momento das exposições dos resultados dos projetos.

\section{Considerações Finais}

Este artigo apresentou um relato das experiências da aplicação da metodologia de Ensino com Pesquisa como forma de aprimoramento da prática docente. Como campo prático, a metodologia foi aplicada na turma de ingressantes do Curso Técnico em Informática Integrado. Foram criados dois projetos de pesquisa os quais embasaram todas as atividades desenvolvidas em sala de aula. Estes projetos foram criados a partir de reflexões realizadas sobre o Plano de Ensino da disciplina, criando percursos investigativos que deveriam ser percorrido pelos alunos, fomentando a (re)construção dos conhecimentos a serem trabalhados. No geral, a experiência se mostrou positiva em muitos aspectos, apresentando-se como uma boa alternativa para os docentes como metodologia de ensino. Como principais benefícios, observou-se: (1) o aumento da participação dos alunos, (2) uma melhor organização das atividades e um melhor entendimento por parte dos alunos de como os conteúdos se relacionam, (3) a atuação do professor como orientador das atividades, (4) a valorização do percurso dos alunos ao longo das etapas de pesquisa desenvolvido ao longo das aulas, resultando em um processo avaliativo que leve em conta, de maneira mais clara, o caminho percorrido como um todo. Desta forma, grande parte dos benefícios previsto na fundamentação da 
teoria de Ensino com Pesquisa foram verificados ao longo da experiência de aplicação. Juntamente com os aspectos positivos, alguns pontos precisam ser levados em consideração: a aplicação da metodologia em turmas com muitos alunos e a pouca maturidade dos alunos podem prejudicar o bom andamento do processo de ensino-aprendizagem.

Como trabalhos futuros, a aplicação da metodologia de Ensino com Pesquisa no contexto de outras disciplinas da área de computação está planejada. Cada componente curricular em específico da área profissional abre portas para inúmeras potencialidades de proposições de percursos investigativos aos estudantes. Além disso, a integração destes projetos de pesquisa com temáticas de outras áreas do curso apresenta grandes possibilidades para contribuir com a formação de indivíduos de maneira cada vez mais integral e completa.

\section{Agradecimento}

Agradecimento ao Instituto Federal do Rio Grande do Sul pelo apoio financeiro para a participação e apresentação deste trabalho na conferência.

\section{Referências}

ANDRADE, L. M.; SILVA, F. Tecnologias da Informação e Comunicação: As Influências das Novas Tecnologias perante a Sociedade. Anais do $4^{0}$ Seminário Nacional O Profesor e a Leitura do Jornal, 2008.

BECKER, F.; MARQUES, T. B. I. (Orgs.), Ser Professor é Ser Pesquisador, Porto Alegre: Mediação, 2007, 136p.

BRANDÃO, J.; NEVES, J. Aplicação da metodologia ativa "Peer Instruction" em um curso técnico em informática. Anais do IX Workshop de pós-graduação e pesquisa do centro Paula e Souza. 2014.

DEMO, P. Pesquisa: princípios científico e educativo. 2. ed. São Paulo: Cortez: Autores Associados, 1991.

DEMO, P. Educar pela Pesquisa. Campinas: Autores Associados, 2011.

LIMA, M. Ensino com Pesquisa: uma revolução silenciosa. São Paulo: M. Lima, 2000.

LIMA, S.; DA SILVA, E.; ALVES, V.; CASTANHO, C.; ESPINDOLA, P.; BACHINSKI, R. Aplicação de uma Metodologia Ativa para o Ensino de Lógica de Programação. Anais do Encontro Anual de Tecnologia da Informação e STIN Simpósio de tecnologia da Informação da Região Noroeste do RS. p. 209-212. 2016.

LUCKESI, Cipriano Carlos. Avaliação da aprendizagem escolar: estudos e proposições. 22.ed. São Paulo: Cortez, 2011.

POZO, J.; CRESPO, M. A aprendizagem e o ensino de ciências: do conhecimento cotidiano ao conhecimento científico. 5 ed. Porto Alegre: Artmed, 2009.

SANTOS, R. P. ; COSTA, H. A. X. Análise de Metodologias e Ambientes de Ensino para Algoritmos, Estruturas de Dados e Programação aos iniciantes em Computação e Informática. Anais do INFOCOMP - JOURNAL OF COMPUTER SCIENCE, Lavras/MG - Brasil, v. 5, n. 1, p. 41-50, 2006. 